\title{
The new oil?
}

\section{Supply concerns over rare-earth elements mined in China are worrying the rest of the world.}

Throughout history, political fights and international wars have often been waged over securing valuable resources such as oil, water and food. Now, a group of 17 elements in the periodic table known collectively as the 'rare earths' (named so because they were first found within rare minerals buried deep underground) are at the centre of a political storm that threatens the photonics industry.

Although the importance of the rare earths may not be immediately obvious - after all, we don't eat, drink or power our cars with them - the reality is that they are the lifeblood of the photonics industry, which would almost certainly collapse without them. Elements such as erbium, ytterbium, yttrium, neodymium, thulium and europium are vital optically active ingredients at the heart of many lasers, optical amplifiers and phosphors. Put simply, rare earths transform otherwise benign crystals, glass fibres and thin films into materials that are capable of emitting and amplifying light. For many working in the optics sector, a world without rare earths is unthinkable; it would be a world without the erbium-doped fibre amplifier used to overcome losses in long-distance optical communication links, without many phosphors found in image intensifiers and white-light LEDs, and without the Nd:YAG laser, to name just a few obvious examples. The consequences for telecommunications, the laser industry and optoelectronics in general would be devastating. Beyond photonics, rare earths are also in used magnets, batteries and lightweight metal alloys.

Securing the supply of these vitally important elements is therefore essential to the photonics industry. China is currently the world's dominant and effectively exclusive supplier of rare earths, having not only the largest deposits of any single country but also the largest mining operations. The problem is that in 2010 China almost halved its export quotas for rare earths, provoking supply worries in other parts of the world. Although this is unlikely to impact academic research given the small quantities usually required, it could have far more serious ramifications for industry.

According to Reuters ${ }^{1}$, China produces almost all of the world's supply of rare earths, and in 2010 set its export quotas at a level $40 \%$ lower than that of 2009 . The

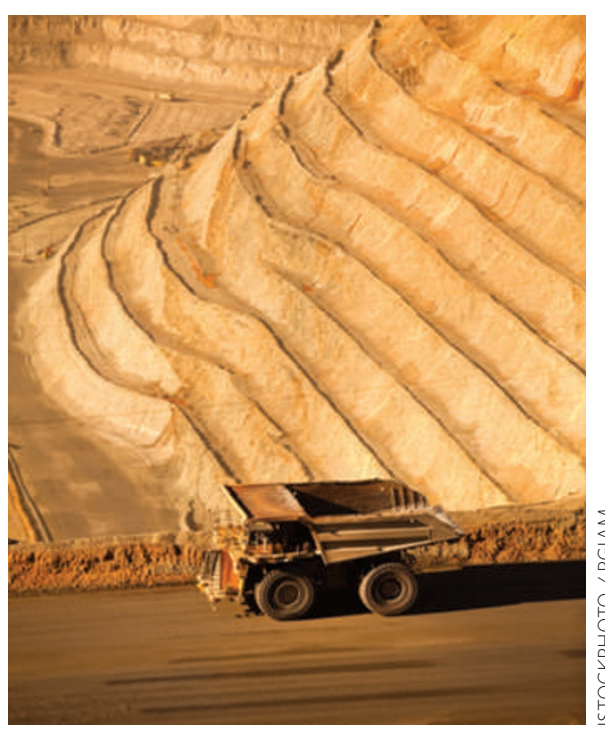

buried beneath US soil actually total around 1.5 million tonnes. These deposits would be sufficient to support domestic supply in principle, as annual consumption is only around 10,000 tonnes. The problem, however, is that there are currently no operational mines available to extract this resource, and opening new mines is a potentially slow and expensive process that is fraught with difficulties.

\section{"During the past 50 years outside of China, there has been little rare-earth element exploration and almost no mine development."}

Rare-earth deposits were first discovered at Mountain Pass in 1949, and mining official response from Chinese government officials is that China is intending to crack down on illegal mining activities and excessive mining above quotas, which effectively create a black market for rare earths. In the first nine months of 2010, China exported 32,000 tonnes of rare earths, with around half of this going to Japan. The situation then took a turn for the worse at the end of September when China imposed a temporary ban on all rare-earth exports to Japan, following territorial disputes.

A recent report from the US Geological Survey $^{2}$ analysing the global supply situation for rare-earth deposits explains the concern: "At the present time, the US obtains its rareearth element raw materials from foreign sources, almost exclusively from China. Import dependence on a single country raises serious issues of supply security."

The report also states that in 2009, China produced $95 \%$ of the world's rare-earth elements and accounts for $36 \%$ of the world's reserves. One of the most important mining towns in China is Bayan Obo in Inner Mongolia. This single mine is responsible for almost half the world's supply of rare-earth elements.

Interestingly, however, this wasn't always the case. Prior to 1998, when the Mountain Pass mine in California (the only rare-earth mine in the USA) ceased production, US industry was able to source many rare-earth elements from domestic means. The report estimates that rare-earth oxide deposits began just four years later. "That was more than 50 years ago, and is not indicative of the time required to discover and develop rare-earth element deposits in today's regulatory climate," comments the report. "During the past 50 years outside of China, there has been little rare-earth element exploration and almost no mine development."

Although the cost of reopening the Mountain Pass mine are estimated to be as large as US $\$ 0.5$ billion, Molycorp Minerals, the mine's owner, has stated that it intends to "bring the facility back into full production following an extensive modernization and expansion project." Indeed, if all goes well the mine could be up and running again in the second half of 2011. The alternative finding other deposits and opening new mines - is anticipated to take several years or longer in the case of engineering, financial or legal issues.

"Unfortunately, the time required to develop new rare-earth element mines is of the order of at least a decade, perhaps much longer in the USA, and forecasting supply that far into the future is hazardous," concludes the report. "Developing a new mine requires a prolonged effort of prospecting, exploration, process development, feasibility studies, permitting, construction and commissioning."

References

1. www.reuters.com/article/idUSTRE6AK0R620101121

2. http://pubs.usgs.gov/sir/2010/5220 